\title{
Case Report: Endovascular Repair of Iatrogenic Subclavian Artery Pseudoaneurysm
}

\author{
Ng Yau Piow and Alan Koay Choon Chern* \\ Peripheral and Vascular Unit, National Heart Institute (IJN), Malaysia
}

Submission: November 22, 2017; Published: December 12, 2017

*Corresponding author: Alan Koay Choon Chern, Peripheral and Vascular Unit, National Heart Institute (IJN), Malaysia, Email: alankoay81@gmail.com

\section{Introduction}

Subclavian artery pseudoaneurysm is an uncommon clinical entity with only a few cases reported in the literature. Most cases are related to injuries of the subclavian artery during insertion of central venous catheter. In some of these cases, the injury is secondary to blunt trauma. We report an interesting case of iatrogenic right subclavian artery pseudoaneursym secondary to a complicated central vein dialysis catheter insertion, which was successfully treated with endovascular stenting and resulted in clinical improvement.

\section{Case Report}

A 60-year-old gentleman with a background history of accelerated hypertension and chronic kidney disease developed worsening renal function secondary to Enterococcus septicemia, following an admission for Steven-Johnson syndrome. The oliguric renal failure did not respond to fluid challenge and eventually required hemodialysis. Internal jugular venous catheterizations were attempted without ultrasound guidance on both the left and right neck with a $12.5 \mathrm{Fr}$ dual lumen catheter, but were unsuccessful. A right femoral vein catheter was then inserted and dialysis proceeded without any complications. After a week, he was discharged well with stable renal function but presented again a month later with a complaint of right neck swelling, which gradually deteriorated over the last one month. This was associated with stridor and difficulty in breathing. Physical examination revealed a protracted and ill man with stable vital signs. He had audible stridor but was not in respiratory distress. A large anterolateral mass was observed on the right side of the neck and measured approximately $15 \times 10 \mathrm{~cm}$. The mass was tender, pulsating and occupied the entire right supraclavicular fossa and posterior triangle. Besides, he also had right upper limb edema, however, the distal arterial circulation was not compromised.

A computed tomography (CT) scan of the head, neck and thorax was performed urgently and it revealed a large pseudoaneurysm arising from the proximal right subclavian artery with surrounding hematoma. The right vertebral and internal mammary arteries (RIMA) originated just slightly proximal to the neck of the pseudoaneurysm, but from the superior and inferior walls of the right subclavian artery respectively. In addition, there was evidence of mass effect to the trachea and the ipsilateral right internal jugular vein (Figure 1). Subsequent to that, he was referred to the interventional cardiologist for further treatment. Endovascular subclavian artery stenting was offered, to which he agreed.

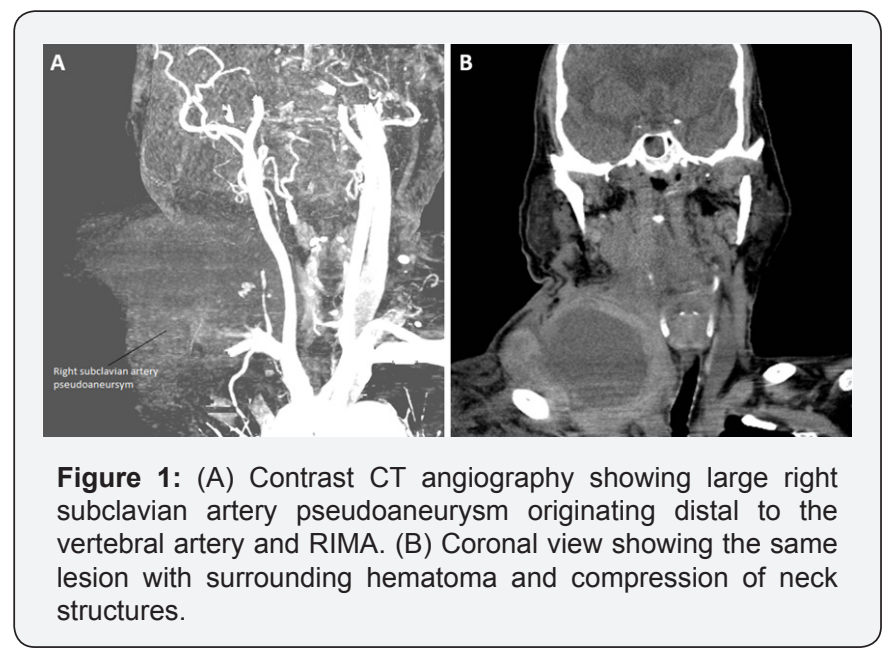

The procedure was performed under local anaesthesia through the right femoral artery using a 6 French Terumo vascular sheath. Intra-arterial bolus heparin $2000 \mathrm{u}$ was administered and a 0.035 " Terumo glide wire was advanced into the right subclavian artery. Multiple attempts were made to advance a Judkins Right diagnostic catheter into the right subclavian artery but to no avail. Eventually, a 6 French Terumo Glidecath was able to advance into the right subclavian artery, but it was also kicked out when attempting to exchange the 0.035 " Terumo glide wire to a 0.035 " Terumo stiff wire for better support. A decision was then made to puncture the right radial artery with the aim of snaring the 0.035 " Terumo glide wire through it. 
This was carried out using a 9 French Mullins sheath through the right femoral artery and snaring of the 0.035 " Terumo glide wire through the right radial artery access. With the counter traction applied at both ends of the glide wire, an Advanta V12 $9 \times 38 \times 120 \mathrm{~mm}$ covered stent was then advanced to the right subclavian artery and deployed immediately distal to the vertebral artery. The following right subclavian angiography still showed the presence of pseudoaneurysm (Figure 2). A second Advanta V12 10x38x120mm covered stent was deployed overlapping with the first stent, across the right vertebral and internal mammary arteries (RIMA). This successfully sealed off the pseudoaneursym and achieved immediate angiographic success (Figure 3). The patient subsequently made an uneventful recovery with no signs to suggest any compromise to the cerebral perfusion.

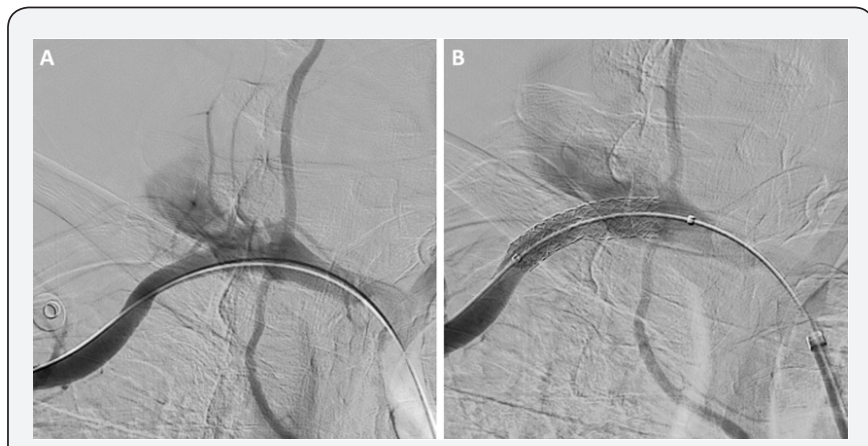

Figure 2: (A) Right subclavian arteriography confirming the pseudoaneurysm as seen on CT scan. (B) Persistent pseudoaneurysm after deployment of the first covered stent.

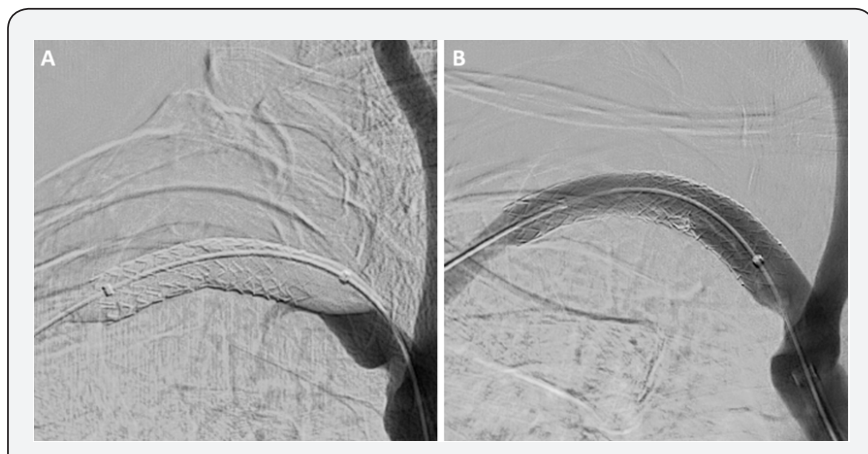

Figure 3: (A) Stent balloon pulled back and inflated to determine the proximal location of the neck of pseudoaneurysm. (B) Pseudoaneurysm completely sealed off after deployment of second covered stent with jailing of right vertebral artery and RIMA with no detrimental consequences.

\section{Discussion}

Accidental arterial puncture occurs in $1 \%$ to $2.7 \%$ of jugular and subclavian venous approaches [1,2]. Management of complications arising from carotid, subclavian or brachiocephalic arterial puncture from attempted jugular venous cannulation can be challenging. The risk of considerable bleeding, embolic phenomenon associated with arterial catheterization, and the noncompressible anatomic location at the base of the neck preclude the direct removal of the catheter. Arterial catheterization should be suspected immediately when pulsatile backflow of welloxygenated blood or local swelling is detected. Delayed diagnosis increases the risk of serious complications as seen in this case. Endovascular treatment with covered stent grafts, percutaneous closure devices and pseudoaneurysm embolization will have been reported provide good results when selected appropriately on imaging evaluation $[3,4]$. In this case, a decision was made to cover the origin of major branches vertebral artery and RIMA in order to ultimately achieve a complete seal of the pseudoaneusrym, which was persistent even after the deployment of first covered stent.

Radiological imaging plays a crucial role in the evaluation of arterial injuries due to central venous cannulation. With high resolution multi-sliced CT scan, vascular anatomy can be clearly delineated and planning of treatment strategy. Long-term outcome in terms of restenosis, stent fracture is unknown although recent findings suggest that they are comparable to open surgical repair [5]. A recent literature review of management options of inadvertent arterial puncture during central venous cannulation described high success rate using covered stents, closure devices and thrombin injection [6].

\section{Conclusion}

In conclusion, this case described an angiographic and clinically success of endovascular stenting in a patient with iatrogenic right subclavian artery pseudoaneursym with two covered stent grafts. Jailing of the right vertebral artery and RIMA resulted in no detrimental consequences. In conclusion, percutaneous endovascular stenting is an attractive treatment option for subclavian arterial injuries and should be considered the first option in suitable patients.

\section{Learning Points}

1. Real-time ultrasound-guided catheterization should be employed in all central venous punctures to prevent inadvertent subclavian arterial injury.

2. Recognition of inadvertent arterial puncture should be made earlier to prevent fatal outcomes.

3. Covered stent graft is an attractive approach in endovascular treatment of iatrogenic subclavian artery pseudoaneursym.

\section{Acknowledgement}

This project has obtained the approval of the ethics committee and institutional review board of National Heart Institute (IJN), Malaysia.

\section{References}

1. Eisen LA, Narasimhan M, Berger JS, Mayo PH, Rosen MJ (2006) Mechanical complications of central venous catheters. J Intensive Care Med 21(1): 40-46.

2. Iovino F, Pittiruti M, Buononato M, Lo Schiavo F (2001) Central venous catheterization: Complications of different placements. Ann Chir 126(10): 1001-1006. 
3. Szkup PL (2012) A minimally invasive technique for closing an iatrogenic subclavian artery cannulation using the Angio-Seal closure device: Two case reports. J Med Case Rep 6: 82.

4. Pikwer A, Acosta S, Kolbel T, Malina M, Sonesson B, et al. (2009) Management of inadvertent arterial catheterization associated with central venous access procedures. Eur J Vasc Endovasc Surg 38(6) 707-714.
5. Toit DDF, Lambrechts AV, Stark H, Warren BL (2008) Long-term results of stent graft treatment of subclavian artery injuries: Management of choice for stable patients. J Vasc Surg 47(4): 739-743.

6. Jaoudeh AN, Turba UC, Arslan B, Hagspiel KD, Angle JF, et al. (2009) Management of subclavian arterial injuries following inadvertent arterial puncture during central venous catheter placement. J Vasc Interv Radiol 20(3): 396-402.

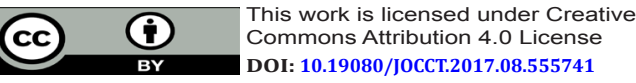

\section{Your next submission with Juniper Publishers will reach you the below assets}

- Quality Editorial service

- Swift Peer Review

- Reprints availability

- E-prints Service

- Manuscript Podcast for convenient understanding

- Global attainment for your research

- Manuscript accessibility in different formats

( Pdf, E-pub, Full Text, Audio)

- Unceasing customer service

Track the below URL for one-step submission https://juniperpublishers.com/online-submission.php 